\title{
Simulation and Optimization of wheel Hub and Upright of Vehicle: A Review
}

\author{
Gaurav Saxena ${ }^{1}$, Ankit Singh Chauhan ${ }^{1}$, Rohit Jain ${ }^{1}$, Ishwar Gupta ${ }^{2}$ \\ ${ }^{I}$ Department of Automobile Engineering, Rustam Ji Institute of Technology, BSF Academy, Tekanpur, Gwalior \\ (M. P.) 475005, India \\ ${ }^{2}$ Department of Mechanical Engineering, Institute of Technology and Management, Gwalior, Madhya \\ Pradesh, 475001, India
}

\begin{abstract}
This paper deals with various methodologies adopted by present researcher for analysis of wheel hub and upright assembly with main objective of analysis and optimization of the vehicle. This review will assist researchers working in the field of development of the structural design and mass reduction of vehicle through optimization methods conducted by FEA software viz. CreO 1.0 and HyperWorks. The review includes key areas of researches as shape optimization, static load analysis and fatigue load analysis using FEA. This literature progressively discusses about the research methodology, softwares and the outcomes of the discussed researches and is intended to give the readers a brief variety of the researches carried out on the wheel hub and upright assembly.
\end{abstract}

Keywords: wheel hub and upright, FEA, Factor of safety, materials.

\section{Introduction}

Wheel hub and upright assembly is a very critical part of the vehicle suspension system which allows the steering arm to turn the front wheels and support the vertical weight of the vehicle [2, 20]. Upright is also known as the knuckle. It assembles with the front tire and a spindle that rotates in a stable plane of motion by a suspension assembly. The force exerted on hub and upright assembly are of the cyclic nature as the steering arm turned [26]. To have the maximum speed for the sports car the weight has to be minimized, therefore while designing the sports car the designers keep this as key factor and design the vehicle for minimum weight and maximum stress and force sustaining ability [9].

The design of wheel hub and upright are one of the important parameters in optimizing the weight of the vehicle. In fig.1 basic type of hub is shown. The mass reduction without compensating the strength of the wheel hub and upright assembly is done by the researchers to optimize the weight of the vehicle. Weight or mass of the vehicle can be reduced by improving technology such as material selections, design and analysis method and optimization method [10]. Steering upright subjected to time varying load during service life, leading to fatigue loads [13]. The hub and upright assembly also transfers the whole weight of the vehicle into wheels, which lead to stress on mountings. Wheel hub and upright can be analysed without due consideration to bearing design [3].

\section{Brief Description To Hub And Upright}

In automotive suspension, a steering upright is that part which contains the wheel hub or spindle, and attaches to the suspension components, variously it is known as steering knuckle, spindle, upright or hub.

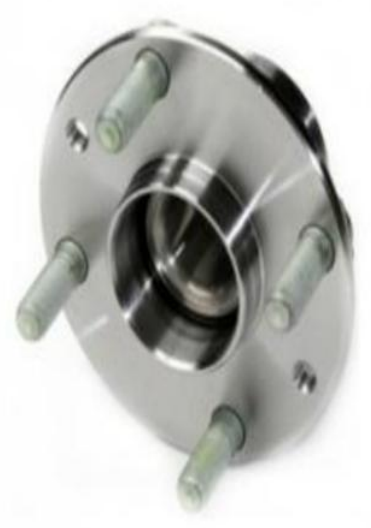

Fig. 1. Basic Type of Hub as reported by ref. [4] 
The wheel and tire assembly attach to the hub or spindle of the knuckle where the tire/wheel rotates while being held in a stable plane of motion by the knuckle/suspension assembly [3]. As shown in fig.2 of double- wishbone suspension, the knuckle is attached to the upper control arm at the top and the lower control arm at the bottom. The wheel assembly is shown attached to the knuckle at its centre point. Suspension systems in any vehicles uses different types of links, arms, and joint to let the wheels move freely, front suspensions also have to allow the front wheel to turn [27]. Steering knuckle/spindle assembly, which have two separate or one complete parts attached together in one of these links. Hub is the part attached to upright, the purpose of a wheel hub is to attach a wheel to a motor shaft. Hubs are also used to attach lifting arms, release doors and pulleys to motor shafts [28]. Wheels are typically attached to hubs via the wheels face or its centre. The wheel is attached through fasteners to hub due to a good strength and can be easily removed for storage or servicing. Hubs are typically attached to the motors by closely sliding over and locking into engagement with

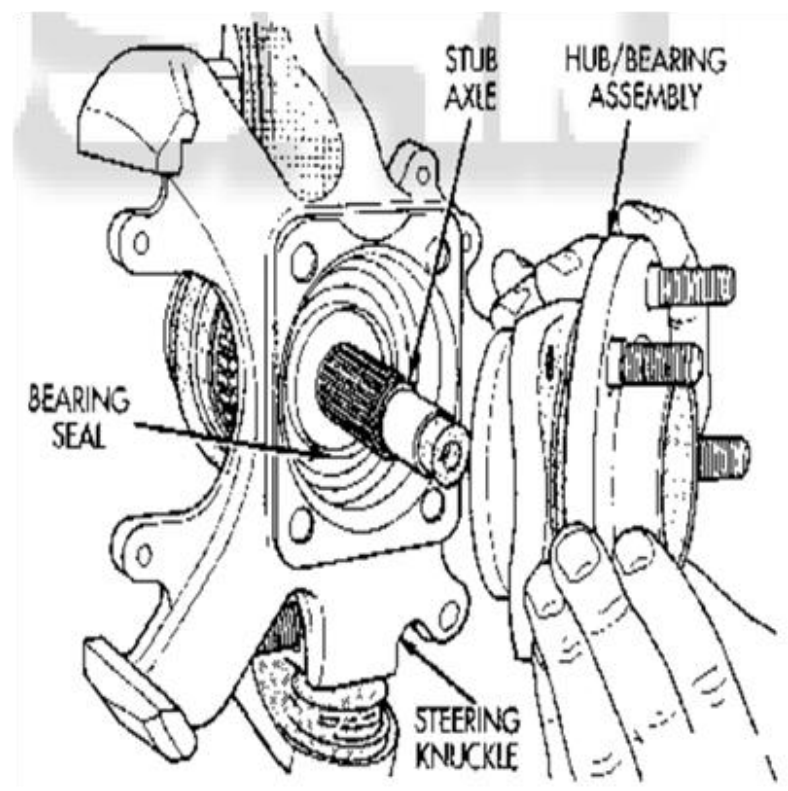

Fig. 2.Component of wheel hub and upright as reported by ref. [26]

their shafts transferring torque from the motor, through the hub and to the wheel. Hub must be capable of rigidly supporting its share of the total weight of a vehicle without failure during its expected life span. If the hub geometry and material selection are inadequate, it will break assembly which cannot be repaired [29].

\subsection{Introduction}

\section{Previous Researches}

The hub and upright assembly is a complex structure to examine [9]. The hub and upright are stressed throughout their life during load. In the process of operation, hub and upright assembly is subjected to fatigue, cornering force, braking force, bump, impact load and combination of all forces due to bump and cornering process, whereas it is subjected to shock load due to excessive vibrations in the hub and upright in off road conditions [20]. So it is necessary to study about the stress-strain distribution, fatigue and vibration characteristics of the hub and upright assembly under above mentioned conditions [17]. Most of the researches on the hub and upright in past few years are done using Finite Element Methods (FEM). Several researchers have conducted a variety of different analysis on the hub and upright assembly using different FEA tools. The primary aim of this article is to provide a comprehensive literature review of researches conducted on the hub and up- right assembly which emphasis on design, structural analysis, fatigue life prediction, and structural optimization through CAD/CAE system integration of the hub and upright assembly with the focus on analysis technique employed.

\subsection{Work carried out on the design on hub and upright}

For the selection of $\mathrm{a}$ hub and upright assembly, weight is an important parameter. Fuel consumption can be reduced by using light weight design approach while keeping the required strength same. Some researcher attempted to reduce the weight of the hub and upright, in this field first significant study to 


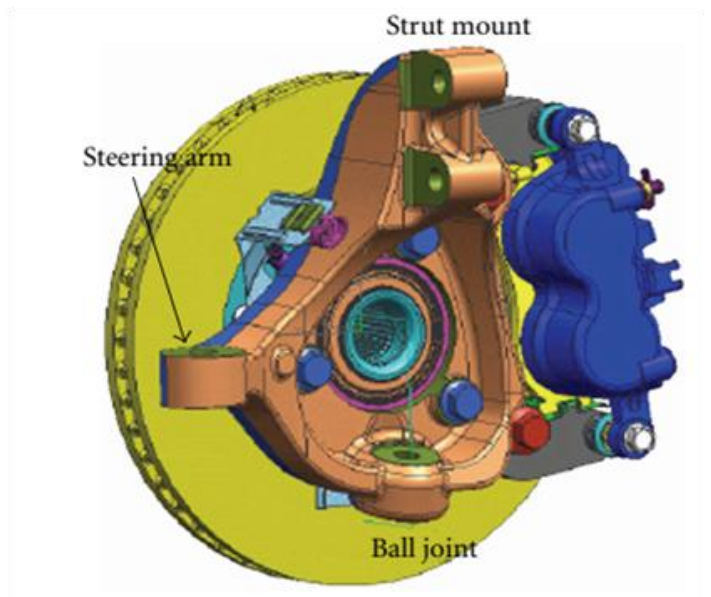

Fig. 3.Steering Knuckle System as presented by ref.[17]

reduce the upright weight, was done by Suhaimi [1],through static analysis some parts of upright were eliminated maintaining permissible structural strength through stages such as designing, analysis, fabrication and fitting and 55.82 percent of weight reduction was achieved. Similarly, Kulkarni and Tambe [2] developed Finite Element Model in HyperWorks and the Model was solved using RADIOSS solver. OptiStruct solver was used for performing topology optimization to minimize the amount of material to be used and setting geometric parameters as design variables. They reduced the mass of the existing steering knuckle to $53.33 \%$. The maximum stresses and displacement were within the permissible limit and yield- ing factor of safety around 2.8 to 3 .

Razak et al. [3], carried out analysis for lightweight and optimized design of steering knuckle using aluminium 6061- t5 alloy (yield strength $276 \mathrm{mPa}$ ). They concluded Aluminium 6061-t5 alloy to be the best material for the component due to better physical and mechanical properties as well as lightweight nature. They reduced weight of existing knuckle by $45.8 \%$, while conforming the desired strength requirement.

Dyapa and Shenoy [4] carried out modal analysis using unsprung mass, to improve the dynamics of the vehicle. They concluded that the steel upright can definitely replace aluminium without affecting the performance and making the cars very economical. Research in similar context was carried out Gill et al. [5], they proposed new design using adapter plates which meets all the requirements of design maintaining stresses well below the yield strength of the material. Later manufacturing through 7075-t6 aluminium was carried out using velocity machining. The research provides the new design as a replacement for conventional design of upright.

\subsection{Work carried out on the structural analys is of hub and upright assembly}

The hub and upright assembly is subjected to complex stress due to carrying load reacted by the wheels, which are transmitted to the chassis through the A-arms indirectly from the upright. Hence, nature of the load is bending [1]. In this process, a variety of force act on the hub and upright assembly [20]. Therefore, it is necessary to make the strength calculation of hub and upright assembly under load condition [26]. Structural analysis determines the area under high stresses and provides a basis for structural optimization which improves service life.

Song and Lee [6] discussed Reliability-Based Design Optimization (RBDO) of an automotive knuckle component under bump and brake loading conditions. The probabilistic design minimized the weight of a knuckle component subjected to stresses, deformations, and frequency constraints in order to meet the given target reliability. Later on Babu et al. [7] achieved load analysis in two steps, first modeling of steering knuckle as per design parameters and also analysis considering the loads and boundary conditions. They find out the minimum stress area. In another research Rangababu et al. [8] carried out analysis on three materials viz. GCR15, Steel and Low Alloy Martensitic Chrome Steel, with conventional model and Fiat model. They upgrade both conventional model and Fiat model. The results obtained for von misses stress, strain and total deformation values were compared as shown in table 2. GCR15 (alloy steel) was suggest as most suitable material.Statical analysis and optimization of upright was done by Prajwal [9] through FEA software Hypermesh. After optimiza- tion the weight was reduced up to $5 \%$ and stress concentration was reduced up to 15\%. In similar context researchers, Tagade et al [10] extended the scope of static analysis of previous researchers. In analysis geometric modeling was done on CREO 2.0 and ANSYS. The analysis concluded with mass reduction of knuckle by $67 \%$ maintaining factory of safety between 3 to 4 . 
Using similar methodology Sharma [11] used CREO2.0 for geometric modeling and later carried out Static analysis on ANSYS WORKBENCH.In analysis of upright, load applied due to braking torque on caliper mounting, longitudinal reac- tion due to traction, vertical reaction due to vehicle weight and steering reaction were considered as applied boundary condi- tions. The final reduction in mass was $19.35 \%$, maintaining factor of safety 3 to 4.Fig. 4 shown detail and meshing of upright model.

Das [12] did static analysis and dynamic analysis on hub and upright using FEA solver SOLIDWORK. Finite Element Analysis was performed on the front hubs to validate their design. Braking force of $1.4 \mathrm{~g}$ was applied to the brake rotor fastener holes. Also, a cornering force of $1.3 \mathrm{~g}$ was simulated by applying a force of $4469.9 \mathrm{~N}$ on the bottom lug hole and $3024.2 \mathrm{~N}$ on the top lug hole in opposite directions while constraining the brake rotor fingers from translating. In analysis factor of safety of hub was maintained under 3.7. Fig. 5 and 6 shows design of hub and its stress analysis respectively.

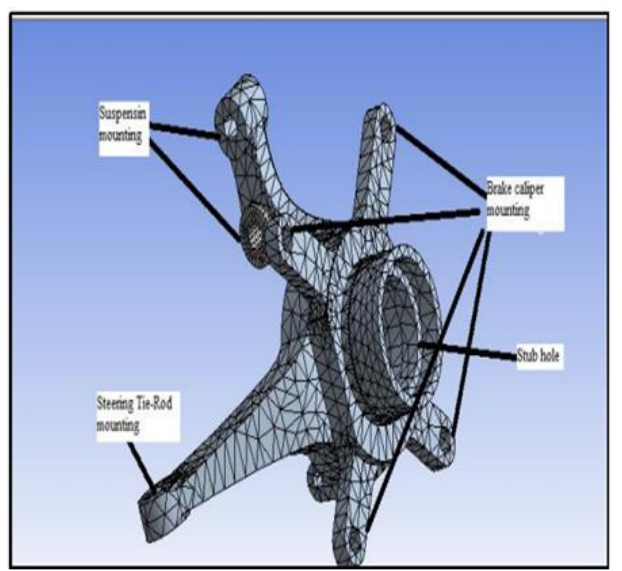

Fig. 4. Detail And Meshing of Upright Model as reported by ref. [11]

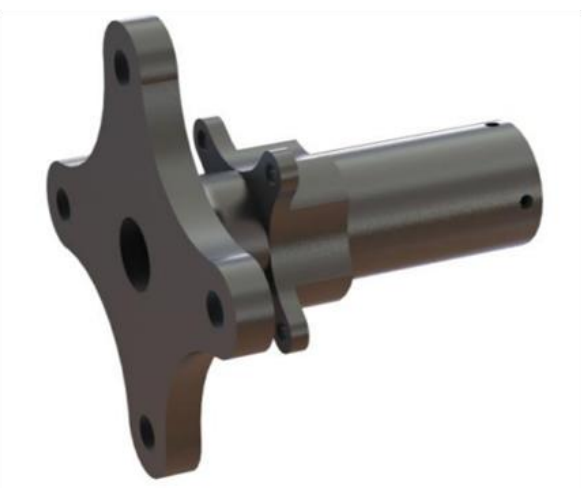

Fig. 5. Design Of Hub as presented by ref.[12]

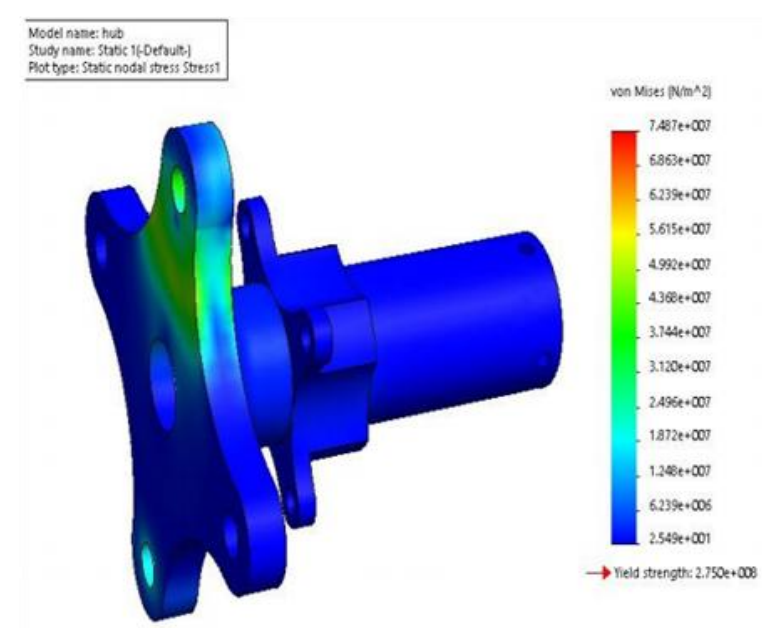

Fig. 6. Stress Analysis On Hub presented by ref.[12] 
TABLE I: Comparison of Results of Fiat Model and Conventional Model With New Fiat Model and Upgrade Conventional Model as Reported by Ref.[8]

\begin{tabular}{|l|l|l|l|l|}
\hline Material & & GCR15 & STEEL & Low Alloy Martensitic \\
\hline \multirow{2}{*}{ Fiat Model } & Total Deformation & 0.41341 & .041739 & .043409 \\
\cline { 2 - 6 } & Stress Intensity & 1355 & 1355 & 1355 \\
\hline \multirow{2}{*}{ Fiat Upgraded Model } & Total Deformation & .041111 & .041506 & .043166 \\
\cline { 2 - 5 } & Stress Intensity & 1351 & 1351 & 1351 \\
\hline \multirow{2}{*}{ Conventional Model } & Total Deformation & .042004 & .042008 & .044104 \\
\cline { 2 - 5 } & Stress Intensity & 1356 & 1356 & 1356 \\
\hline Conventional Upgraded Model & Total Deformation & .041389 & .041787 & .043409 \\
\cline { 2 - 5 } & Stress Intensity & 1357 & 1357 & 1357 \\
\hline
\end{tabular}

\subsection{Work carried out on the fatigue analysis of hub and upright assembly}

The hub and upright are subjected to cyclic loading con- ditions, which results in generation of cyclic stress and ultimately fatigue failure $[11,14]$. Therefore, it is necessary to analyze the fatigue of hub and upright assembly to prevent premature breakdown, failures or fractures. It takes place when applied stress get so large that material can no longer endure stresses and strains. In classic structural analyses, failure predictions were based solely on material strength or yield strength. Durability analysis goes beyond this, evaluating failure based on repeated simple or complex loading [26].

An experimental analysis of fatigue load on material was done by Zoroufi and Fatemi [13]. Three materials of different manufacturing processes viz. forged steel, cast aluminium, and cast iron were used as knuckles. The monotonic and cyclic specimen tests were performed by a $50 \mathrm{KN}$ closed-loop servohydraulic uniaxial testing machine with computer control and hydraulic-wedge grips. Tensile tests and monotonic deformation curves concluded that cast aluminum and cast iron reached $37 \%$ and $57 \%$ ultimate tensile strength, respectively as compared to forged steel. The percent elongation of cast aluminum and cast iron were $24 \%$ and $48 \%$ of the forged steel, respectively. The superimposed curve between SWT and life in cycles is shown in fig.-7.

Later, Chandrakar et al. [14] investigated vehicle steering knuckle undergoing time varying loadings during its service life. They accessed fatigue life and compared fatigue performance of steering knuckles. The better S-N fatigue resistance observed for forged steel, as compared with the two cast materials. Long-life fatigue strengths of cast aluminium and cast iron are only $35 \%$ and $72 \%$ of the forged steel.

Azrulhisham et al. [15] used MATLAB statistical toolbox for calculating probability density function of the Beta distribution of steering knuckle. The function between probability density and fatigue life is shown in fig.-8. They predicted fatigue life reliability for considering the variations in material properties. The shortest life appeared to be in the vertical load direction with the lowest fatigue life reliability between 1400016000 cycles. The results obtained for the highest reliability recorded for cycles between 10000 and 12000 cycles which included the 10891 cycles as calculated by the mean value of material property.

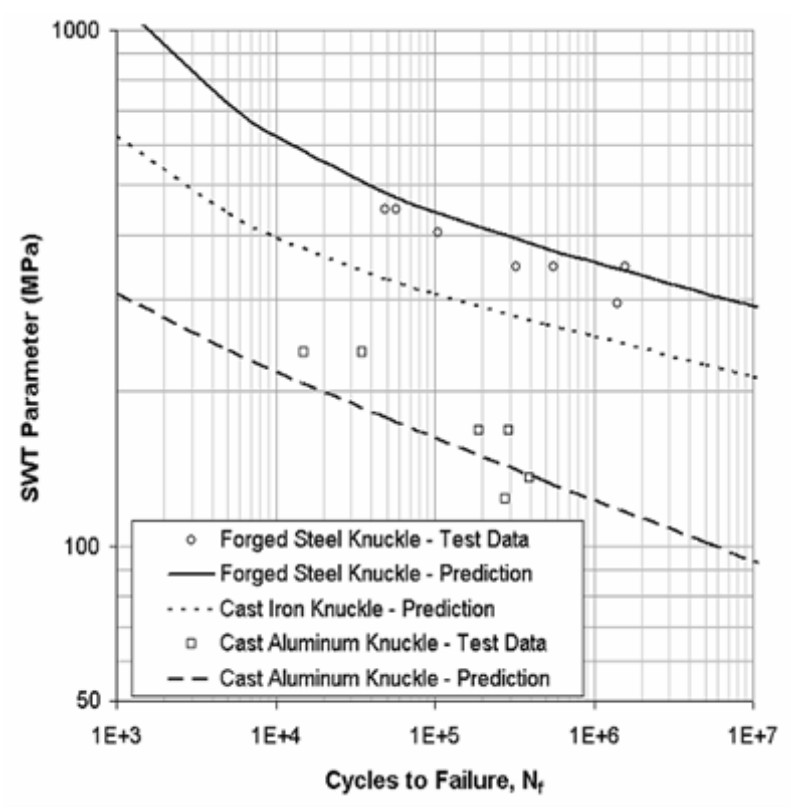

Fig. 7. Superimposed SWT parameter versus life curves based on the strain- life approach for the forged steel, cast aluminum and cast iron knuckles as reported by ref. [13]. 


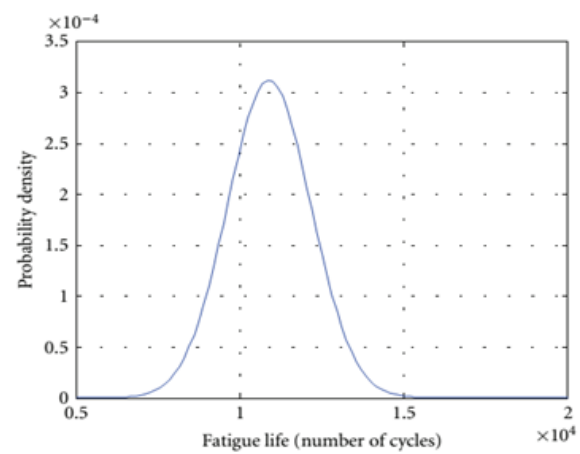

Fig. 8. Probability Density Function of the steering knuckle, presented by [15].

Muhamad et al. [16] reduced mass of an existing steering knuckle component of a local car model by applying shape optimization technique using FEM. Through analysis $8.37 \%$ reduction of mass was obtained in improved design. Even though there were volume reduction and shape changes, maximum stress had not changed significantly. Analysis on Deflection-Strain in steering knuckle was done by Bhokare et al. [17] through experimentation, the gradually increasing load was applied and corresponding deformations were determined. The load v/s defection or load v/s stress is concluded by the help of simulation software used in UTM machine. Geometric model of the machined component was prepared using CATIA V5. The overall weight of the vehicle was reduced and a new variant which was $5 \%$ better than the previous was introduced.

\subsection{Work carried out on the optimization of the hub and upright assembly}

As from the analytical point of view, it is well understood that the optimization of any structure is a very important work for a researcher performing analysis in his field. A significant work in optimization of upright was done by Shelar and Prof. Khairnar [18] by using methodology based on durability and optimized design through probabilistic models of design variables (doe. The obtained data give reduction in weight by $9.195 \%$ with stress $23.67 \%$. Another experimental analysis of optimization through fatigue life was done by Sivananth [19], geometric model developed on SOLIDWORK and analysis carried out on HYPERMESH. In analysis comparison of two material SG (iron alloy) and Al alloy steering arm was done. Regional impact force of $17.5 \mathrm{KN}$ and $35 \mathrm{KN}$ was applied at varying speed. For the velocity of $2 \mathrm{~m} / \mathrm{s}$ the deflection varies between $3.5 \mathrm{~mm}$ to $4.39 \mathrm{~mm}$, which does not affect knuckle ,but in case of SG iron for velocity of $4 \mathrm{~m} / \mathrm{s}, 8.6 \mathrm{~mm}$ deflection was obtained similary $12 \mathrm{~mm}$ of deflection was obtained for Al alloy which largely affect steering knuckle. Dumbre et al. [20] studied steering knuckle by using FEM software HYPERMESH, OptiStruct and Radioss for optimization of the shape of steering knuckle. $11 \%$ of mass reduction without compromising on its structural strength was achieved. Fig.-9 shows the presented displacement contours.

Pawar and Pathak [21] used Catia for CAD modeling and HyperMesh for structural analysis. Various structural parameters such as nodal displacements, stress distribution and fatigue parameters like damage and fatigue life were analyzed on the same FEA solver. S-N curves were analyzed at high cycle fatigue, where the material is subject to cyclical stresses that are predominantly within the elastic range. Test cycle constraint of material survival for more than 1000 cycles was applied to evaluate results.

\subsection{Work carried out on the CAD/CAE technology integration}

Design and development of a wheel hub and upright require lightweight and sturdy components to move fast [7]. Optimization through CAD/CAE is a process to simplify a design to reduce the weight, manufacturing cost without reducing the initial strength of a part [12].

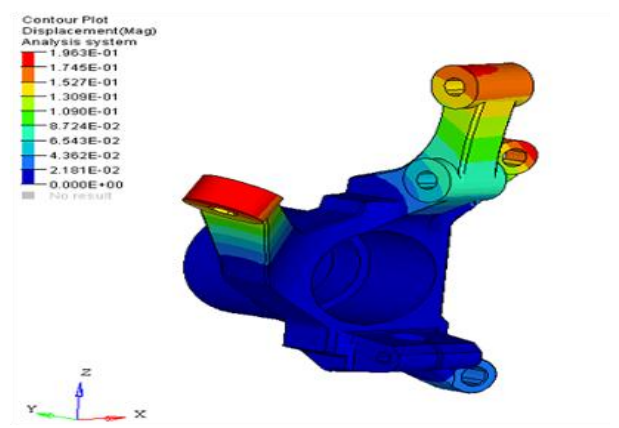

Fig. 9.Displacement Contour Of Modified Model as presented by ref. [20] 


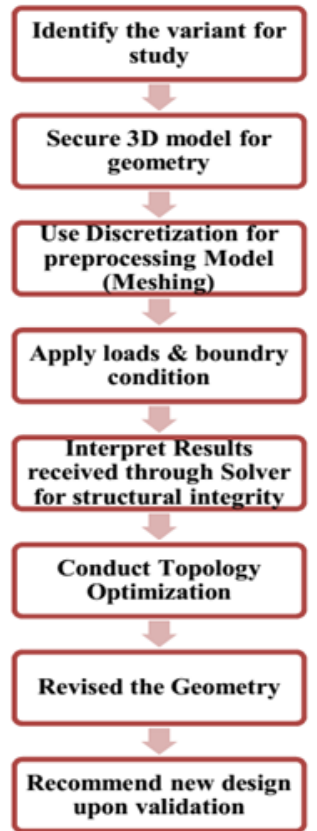

Fig. 10. Design Optimization Flowchart

Fig-10 shows the design optimization flow chart adopted by most of the researchers. Kojima [22] analysed the rear knuckle for the racing car and proposed a new knuckle that was light as well as sturdy. Four methodologies of optimization process namely topology, shape, size and topography optimization were applied. Shape and size optimization was done to obtain final optimum fillets, outer dimensions and thickness of the rear knuckle design. Yuan And Linbo [23] worked on the control arms of knuckle and the steering component which modeled as rigid bodies with software ADAMs, the inertia release method was used to calculate stress/strain of the component. Another researcher Premraj and Palpandi [24] used topology optimization. Analysis was carried out in HyperWorks with the help of OptiStruct solver. Analysis for two different loads were made and maximum stress and deformation was evaluated to carry out topology optimization.They achieved weight reduction upto $2.84 \%$ of the steering knuckle.

Later, Premraj et al. [25] analyzed geometric model of steering knuckle using Catia v5 as modeling tool and HyperWorks 12 as discertization tool later the analysis was carried out on RADIOSS. Different conditions of load were applied to the steering arm. Free vibration modal analysis was done to find natural frequencies and mode shapes of vibration. From the analysis results of design parameters were compared for SG Iron and MDI knuckle. They concluded natural frequency of MDI steering knuckle is less than SG Iron knuckle.

TABLE II: FEA SOLVER, TYPES OF ANALY S IS AND MAIN FINDING OF RE VIEW

\begin{tabular}{|c|c|c|c|c|}
\hline S.NO & AUTHOR & FEA SOLVER & TYPES OF ANALYSIS & MAIN FINDING \\
\hline 1 & $\begin{array}{l}\text { Kulkarni and Tambe } \\
\text { [2] }\end{array}$ & HYPERMESH & $\begin{array}{l}\text { Structure analysis, } \\
\text { Modal analysis }\end{array}$ & $\begin{array}{l}\text { Reduced mass by } 53.3 \% \\
\text { Factor of safety } 2.8 \text { to } 3 \text {. }\end{array}$ \\
\hline 2 & $\begin{array}{l}\text { Razak I.H.A et al. } \\
{[3][30]}\end{array}$ & $\begin{array}{l}\text { SOLIDWORK } \\
\text { SOLIDTHINKING }\end{array}$ & Design optimized & Weight reduction of knuckle by $45.8 \%$ \\
\hline 3 & Dyapa [4] & $\begin{array}{ll}\text { CATIA } & \text { V5 } \\
\text { HYPERMESH } & \\
\end{array}$ & STATIC ANALYSIS & Comparison between two material \\
\hline 4 & Babu et al.[7] & CATIA & $\begin{array}{l}\text { Digitizing steering } \\
\text { knuckle geometry, } \\
\text { Stress (FEA) Analysis, } \\
\text { Modal Analysis }\end{array}$ & $\begin{array}{l}\text { Stress concentration, } \\
\text { Nodal displacements, Stress distribution }\end{array}$ \\
\hline 5 & Rangababu et al. [8] & PRO-E /CREO 2.0 & Static analysis & $\begin{array}{l}\text { Total deformation, } \\
\text { Material Comparison }\end{array}$ \\
\hline 6 & Prajwal et al. [9] & HYPERMESH & Static analysis & $\begin{array}{l}\text { Weight optimization of the upright } \\
\text { Weight is reduced up to } 5 \% \text {, } \\
\text { Stress concentration is reduced up to } \\
15 \% \text {, }\end{array}$ \\
\hline 7 & Tagade et al. [10] & CREO 2.0 ANSYS & Static analysis & $\begin{array}{l}\text { Reduced mass of knuckle by } 67 \% \text {. } \\
\text { Factory of safety is between } 3 \text { to } 4 \text {. }\end{array}$ \\
\hline 8 & Sharma et al. [11] & ANSYS CREO & Static analysis & $\begin{array}{l}\text { Mass reduction by } 19.35 \% \\
\text { Factor of safety } 3 \text { to } 4 \text {. }\end{array}$ \\
\hline
\end{tabular}


Simulation and Optimization of wheel Hub and Upright of Vehicle: A Review

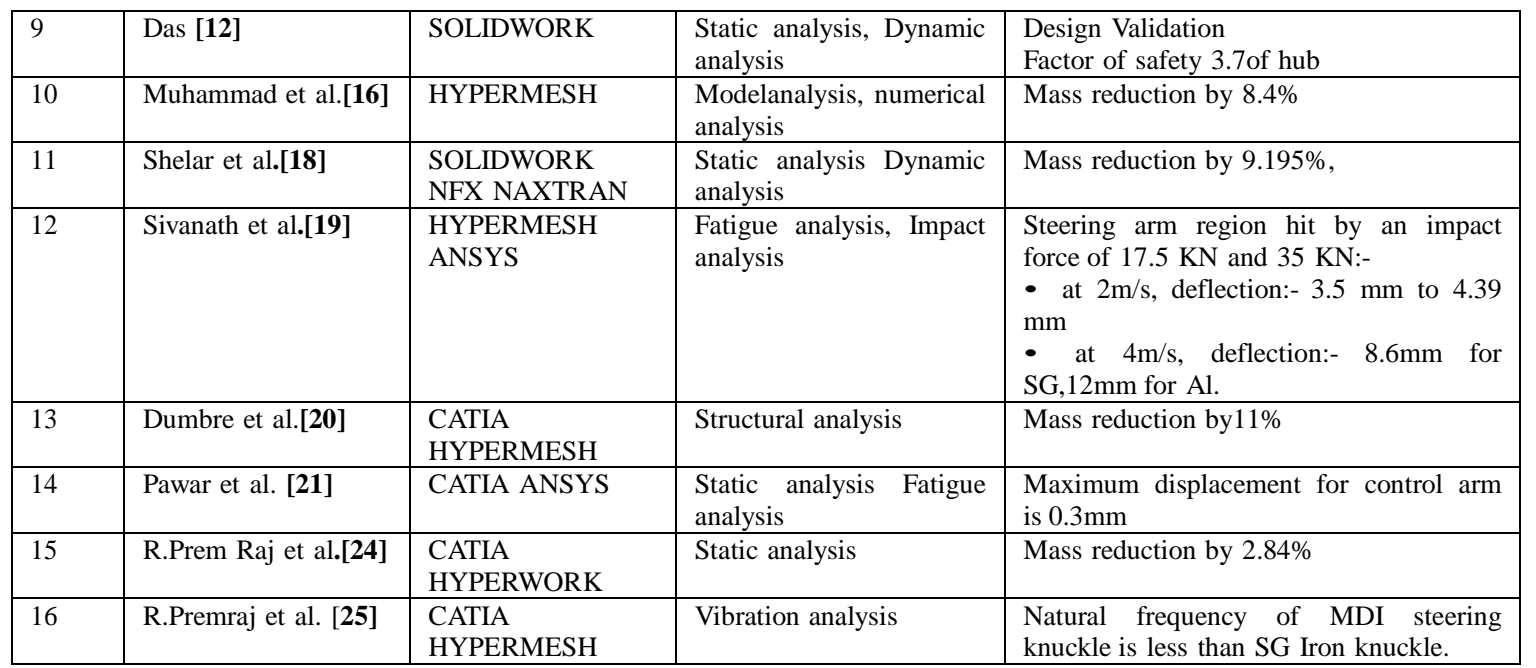

\section{Conclusion}

This work has provided a comprehensive literature review of existing research carried out in terms of design, stress, fatigue, optimization analysis of the hub and upright assembly. An effort has been made to comprise all the important contributions to this area and highlighting the most pertinent literature available for investigating the hub and upright assembly. The concluding remarks and future work from the current literature survey are as follows:-

- From the review of available research on hub and upright assembly, it is apparent that most of the research conducted is purely simulation based on finite element method.

- The FEA is a useful tool since it provides accurate results to access strength and fatigue life of the hub and upright. The same can also be applied for shape optimization of hub and upright

- Mostly FEA of hub and upright assembly were done on mentioned five objectives, simulating actual working conditions in software.

- The review shows that hub and upright are designed for different types of vehicle according to their use. Applied boundary conditions are calculated analytically.

\section{References}

[1]. Suhaimi,Khalis bin.”Design And Fabrication Of An Upright With Brake Caliper Mounting For Formula Versality Race Car" dissertation, april 2011.

[2]. Kulkarni, V. R. and Tambe, A. G.;" Optimizationand Finite Element Analysis of Steering Knuckle”, Altair Technology Conference, 2013.

[3]. Razak I.H.A, Yusop M.Y.M, Yusop M.S.M, Hashim M., Modeling, Simulation And Optimization Analysis Of Steering Knuckle Component For Race Car, International Journal of Research in Engineering and Technology,Volume: 03 Issue: 11, eISSN: 2319- 1163 - pISSN: 2321-7308, Nov- 2014, Pp.221-225.

[4]. Dyapa, Anudeep Reddy and Shenoy,Vishal.,'Design And Analysis Of Upright Of An FIA Related Cruiser Class Solar Electric Vehicle"," International Journal of Engineering Research and Technology (IJERT)", ISSN: 2278-018, oct,2014, Pp.1062-1066.

[5]. Gill, Simren., Hay,Philip., Mckenna, patrick., and Thibodeau, Philippe;"Final Design” Dalhouse Formula SAE " April 8, 2011.

[6]. Song, Chang Yong. and Lee, Jongsoo., Reliability-Based Design Opti- mization Of Knuckle Component Using Conservative Method Of Moving Least Squares Meta-Models, Probabilistic Engineering Mechanics, vol.26 (2011).Pp. 364-379.

[7]. Babu,B., Prabhu,M., Dharmaraj,P. and Sampath,R.," Stress Analysis On Steering Knuckle Of The Automobile Steering System", IJRET: Inter- national Journal of Research in Engineering and Technology,Vol.3,NO.3, eISSN: 2319-1163 - pISSN: 2321-7308, 2014, Pp .363-366

[8]. Rangababu. Daavuluru., Depti, and K., Ramana, B.’Optimal Design And Strenghth Analysis Of Wheel Hub Using Different Type Of Materials" Journal Of Technological Advances And Scientific Research; VOL.1 /ISSUE 04/OCT-Dec 2015;Pp. 353-359.

[9]. Prajwal,Pathri Bhargav. ;"Design Optimization Of Formula One Student Sports Car Upright Using Hypermesh", International Journal Of Mechani- cal And Industrial Engineerin(IJMIE), ISSN No. 2231-6477, vol-2, issue-1, 2012, Pp.54-59.

[10]. Tagade, Poonam P., Sahu, Anil R. and Kutarmare H. C.," Optimization And Finite Element Analysis Of Steering Knuckle” International Journal Of Computer Applications International Conference On Quality Up- Gradation In Engineering, Science And Technology (ICQUEST2015), (0975 8887).

[11]. Sharma,Mahesh P., Mevawala, Denish S., Joshi, Harsh., and Patel,Devendra A.," Static Analysis of Steering Knuckle and Its Shape Optimization ”, IOSR Journal of Mechanical and Civil Engineering (IOSR-JMCE),2014, e-ISSN: 2278-1684, p-ISSN: 2320-334X, Pp. 34-38.

[12]. Das, Abhijeet., "Virtual Prototype Of Upright Assembly Of A Race Car For SUPRA SAEINDIA Competition", International Journal Of Mechanical And Industrial Technology Vol. 2, Issue 2), ISSN 2348-7593, October 2014 - March 2015, Pp: 79-86.

[13]. Zoroufi, Mehrdad. and Fatemi, Ali.," Fatigue Life Comparisons of Com- peting Manufacturing Processes: A Study of Steering Knuckle","SAE Intenational", 2004, 2004-01-0628. 
[14]. Chandrakar, Sharad Kumar., Soni, Dheeraj Lal. and Gardia, Shohel., FEA of A Steering Knuckle for Life Prediction, International Journal of Engineering Research and Technology,Vol.6,No.5, ISSN 0974-3154,2013, Pp.681-688.

[15]. Azrulhisham,E.A., Asri, Y. M., Dzuraidah,A. W., Abdullah, N. M.Nik., Shahrum,A., and Hassan, C. H. Che., Evaluation Of Fatigue Life Reliability Of Steering Knuckle Using Pearson Parametric Distribution Model, International Journal of Quality, Statistics, and Reliability, vol. 2010, Article ID 816407, 8 pages, 2010.

[16]. Muhamad. Wan Mansor Wan.; Sujatmika, Endra; Hamid, Hisham., Torlochan, Faris. "Design Important Of steering Knuckle Component Us- ing Shape Optimization", ”International Journal Of Advanced Computer Science”, Vol2,No.2, 2012, Pp.65-69.

[17]. Bhokare,Kiran S., Kakandikar,G. M.,Kulkarni, Swapnil S., "Predicting The Fatigue Of Steering Knuckle Arm Of A Sport Utility Vehicle While Deploying Analytical Techniques Using CAE", International Journal of Scientific Research and Management Studies (IJSRMS),ISSN: 23493771 Volume 1 Issue 11, Pp: 372-381

[18]. Mahendra L. Shelar and Prof. H. P. Khairnar, Design Analysis and Optimization of Steering Knuckle Using Numerical Methods and Design of Experiments Volume 2, Issue 3, ISSN: 2321- 9939, 2014, Pp. 2958-2967.

[19]. Sivanath,V., Vijayaragana S., and Aswathawan R., "Fatigue and impact analysis of automobile steering knuckle under operation load cases" Altair Technology Conference india 2015.

[20]. Dumbre,Purushottam.,Prof Mishra,A. K., and Aher,V. S., "Structural Analysis of steering Knuckle for Weight Reduction , "International Journal of Emerging Technology and Advanced Engineering", Vol. 4, No. 6, eISSN 22502459 , April-June, 2014, Pp.552-557.

[21]. Pawar, Abhishek,, and Pathak, Charudatta., Fatigue Life Estimation of a Steering Knuckle”, International Engineering Research Journal (IERJ) Special Issue 2, ISSN 2395-1621, 2015, Pp. 1036-1040.

[22]. Y. Kojima, Mechanical Cae In Automotive Design R D Review Of Toyota Crld, Vol. 35, No.4, 2000

[23]. Qu Yuan., Zhang Linbo, Xu Youzhong., Zhang Guanliang., And Wu Shenrong., "Practical Approach of Durability Evaluation for Suspension Knuckle at Different Design Phases", Chery Automobile Co., Ltd "SAE International "2009-01-1411.

[24]. R.Prem Raj , and K.Palpandi, "Static Analysis and Topology Optimiza- tion of Steering Knuckle by Using Finite Element Method" ,International Journal of Innovative Research in Science, Engineering and Technology Vol. 4, Special Issue 13, ISSN:- 2347-6710, December 2015, Pp 374-380.

[25]. R. Premraj M. Chandrasekar K. Arul kumar "Free Vibration Analysis And Optimization Of Streeing Knuckle" South Asian Journal of Engi- neering and Technology Vol.2, No.22, 2016, Pp. 157172

[26]. Patel Akash A.,Fatigue or Durability Analysis of Steering Knuckle”, International Journal for Scientific Research Development, Vol.1, Issue9, ISSN: 2321-0613, 2013

[27]. Chavan, Kamlesh Lalasaheb., Deodas, Sanjay., Kulkarni,Swapnil Shashikant.,” Mass Reduction For Steering Knuckle Arm In A Suspension System Through Topology Optimization In Cae ", International Journal of Advanced Engineering Research and Studies /IV/I/Oct.-Dec,2014,E- ISSN22498974 ,PP 34-35.

[28]. Vishwakarma, Preeti., and Kanungoo, Mukesh.," Finite Element Anal- ysis Of Chervolet Front Hub With The Help Of Inventer" ijite vol. 02, issue -02, ISSN : 2321-1776. Feb. 2010, Pp. 8-16.

[29]. http://www2.mae.ufl.edu/designlab/Lab

[30]. Yusop, M.S.M, Lazim, M.S.M, Razak, I.H.A, Hashim, M.F” Model Development And The Shape Optimization Analysis Of A Rear Knuckle For Race Car ",International Journal of Research in Engineering and Technology vol: 03 Issue: 12, eISSN: 23191163 - pISSN: 2321-7308, Dec-2014, Pp:(172-177). 